\title{
Transcriptome profiling of Elymus sibiricus, an important forage grass in Qinghai-Tibet plateau, reveals novel insights into candidate genes that potentially connected to seed shattering
}

\author{
Wengang Xie ${ }^{*+}$, Junchao Zhang ${ }^{\dagger}$, Xuhong Zhao, Zongyu Zhang and Yanrong Wang*
}

\begin{abstract}
Background: Elymus sibiricus is an important forage grass in semi-arid regions, but it is difficult to grow for commercial seed production due to high seed shattering. To better understand the underlying mechanism and explore the putative genes related to seed shattering, we conducted a combination of morphological, histological, physiochemical and transcriptome analysis on two E. sibiricus genotypes (XH09 and ZhN03) that have contrasting seed shattering.

Results: The results show that seed shattering is generally caused by a degradation of the abscission layer. Early degradation of abscission layers was associated with the increased seed shattering in high seed shattering genotype XH09. Two cell wall degrading enzymes, cellulase (CE) and polygalacturonase (PG), had different activity in the abscission zone, indicating their roles in differentiation of abscission layer. cDNA libraries from abscission zone tissue of XH09 and ZhN03 at 7 days, 21 days and 28 days after heading were constructed and sequenced. A total of 86,634 unigenes were annotated and 7110 differentially expressed transcripts (DETs) were predicted from "XH09-7 vs ZhN03-7", "XH09-21 vs ZhN03-21" and "XH09-28 vs ZhN03-28", corresponding to 2058 up-regulated and 5052 down-regulated unigenes. The expression profiles of 10 candidate transcripts involved in cell wall-degrading enzymes, lignin biosynthesis and phytohormone activity were validated using quantitative real-time PCR (qRT-PCR), 8 of which were up-regulated in low seed shattering genotype ZhN03, suggesting these genes may be associated with reduction of seed shattering.
\end{abstract}

Conclusions: The expression data generated in this study provides an important resource for future molecular biological research in E. sibiricus.

Keywords: Elymus sibiricus, Seed shattering, Abscission layers, Next-generation sequencing, Transcriptome analysis, Mechanism

\footnotetext{
* Correspondence: xiewg@lzu.edu.cn; yrwang@|zu.edu.cn

${ }^{\dagger}$ Equal contributors

State Key Laboratory of Grassland Agro-ecosystems, College of Pastoral

Agriculture Science and Technology, Lanzhou University, Lanzhou, China
} 


\section{Background}

Seed shattering is thought to be an important adaptive trait for seed dispersal in wild plants, but is also a major cause of seed yield loss in many cereal crops [1]. Therefore, the loss of seed shattering is considered one of the key events in the process of most cereals' domestication [2]. Along with other agronomic traits such as thousand grain weight, stress tolerance, and plant height, low seed shattering has been selected as an important agronomic trait in cereal breeding programs.

In cereal grasses, seed abscission occurs in the abscission zone (AZ), and the abscission pathway includes four major steps: abscission zone formation and development, response to abscission signals, activation of abscission, and differentiation of the abscission layer [3]. Previous studies showed seed shattering is generally caused by abscission, and seed retention results from loss of the abscission layers $[4,5]$. The shattering habit is a complex polygenic trait that is controlled by many genes [2, 6]. In Arabidopsis, a MADS-box transcription factor gene STK and a bHLH transcription factor gene $H E C 3$ regulate the formation of seed $A Z s[7,8]$. In rice, several major quantitative trait locus (QTLs) and genes for seed shattering have been identified and cloned, including SH4 [9], qSH1 [2], OsCPL1 [10] and SHAT1 [11]. SH4 is a major seed shattering QTL and encodes a transcription factor with a Myb3 DNA binding domain and a nuclear localizing signal [9]. qSH1 encodes a BEL1-type homeobox gene and regulates pedicel AZ formation, and an single nucleotide polymorphism (SNP) in the 5 ' regulatory region of the $q S H 1$ gene causes loss of seed shattering owing to the absence of abscission layer formation [2]. Rice pedicel AZ formation is also regulated by SHAT1 gene, which is a member of APETALA2 (AP2) family transcription factors [11]. The OsCPL1 gene encodes a protein containing a conserved carboxy terminal domain (CTD) phosphatase domain, which represses differentiation of the abscission layer during panicle development [10]. Additionally, previous research revealed that a variety of genes involved in cell wall degradation and abscissionpromoting phytohormone signaling are up-regulated during abscission $[12,13]$.

In comparison, studies of seed shattering in forage grasses are limited. In hybrid Leymus (Triticeae) wildryes, a major-effect seed retention QTL was identified [14]. A MSDS-box gene WM8 was cloned in Elymus nutans [15]. However, the mechanism of seed shattering in many forage grasses remains largely unexplored and poorly understood. Breeding objectives of forage grasses mainly focus on forage quality, biomass yield, and stress tolerance while seed shattering is relatively unimportant to the end users. The seed shattering habit of many forage grasses has therefore received little attention from forage breeders, despite the fact that seed shattering is a commonly observed trait in many forage cultivars and wild grass species. Previous research has shown that increased seed retention did not influence forage quality, and suggested seed retention would be one of desirable traits in grass seed crops [4]. Selection for seed retention and improvement of seed shattering is critical for forage grasses with a high degree of seed shattering.

Elymus sibiricus (Siberian wild rye), the type species of the genus Elymus, is an economically important perennial cold-season, self-pollinating and allotetraploid forage grass, indigenous to northern Asia [16]. In Qinghai-Tibet Plateau, it is widely used in natural grasslands and cultivated pastures due to its stress tolerance, good forage quality, and adaptability to local environments with low temperature and high altitude [17]. Because of seed shattering, however, E. sibiricus is difficult to grow for commercial seed production. Within the provinces of Qinghai and Sichuan, China, where the vast majority of $E$. sibiricus seed $(2,400,000 \mathrm{~kg})$ is produced each year, the average seed yield is only $690 \mathrm{~kg}$.ha ${ }^{-1}$ due to seed shattering. Indeed, seed shattering can cause up to $80 \%$ yield losses if harvesting is delayed due to adverse conditions [18]. In a previous study, we found wide variation in the tendency for seed shattering among a large spaced-planted population of E. sibiricus, and no significant correlation between seed shattering and other agronomic traits [19]. Those data suggested genetic variation for seed shattering and provided a suitable population from which the molecular mechanisms of seed shattering may be investigated. Although transcriptome analysis based on next-generation sequencing (NGS) has allowed for the elucidation of complex genetic regulatory networks and provided functional data for many genes related to important agronomic traits [20, 21], these tools and sequence resources for seed shattering in $E$. sibiricus are still lacking. This is the first step to investigate the mechanism of seed shattering for this species.

To dissect the mechanism that leads to seed shattering and explore the putative genes related to seed shattering in E. sibiricus, we conducted morphological, histological, and physiochemical measurements coupled with transcriptome analysis on a high seed shattering genotype (XH09) and low seed shattering genotype (ZhN03). The results of this study will lead to a better understanding of the mechanism of seed shattering and would be helpful for breeding improvement programs in seed retention for this species.

\section{Methods}

\section{Plant materials and growth conditions}

The plant materials consisted of two wild E. sibiricus genotypes XH09 and ZhN03 collected from Xiahe and Zhuoni, southern Gansu province, respectively (Fig. 1 a1, a2). E. sibiricus is not an endangered or protected species, thus, no permissions were required for collecting these samples in China. Formal identification of these samples 

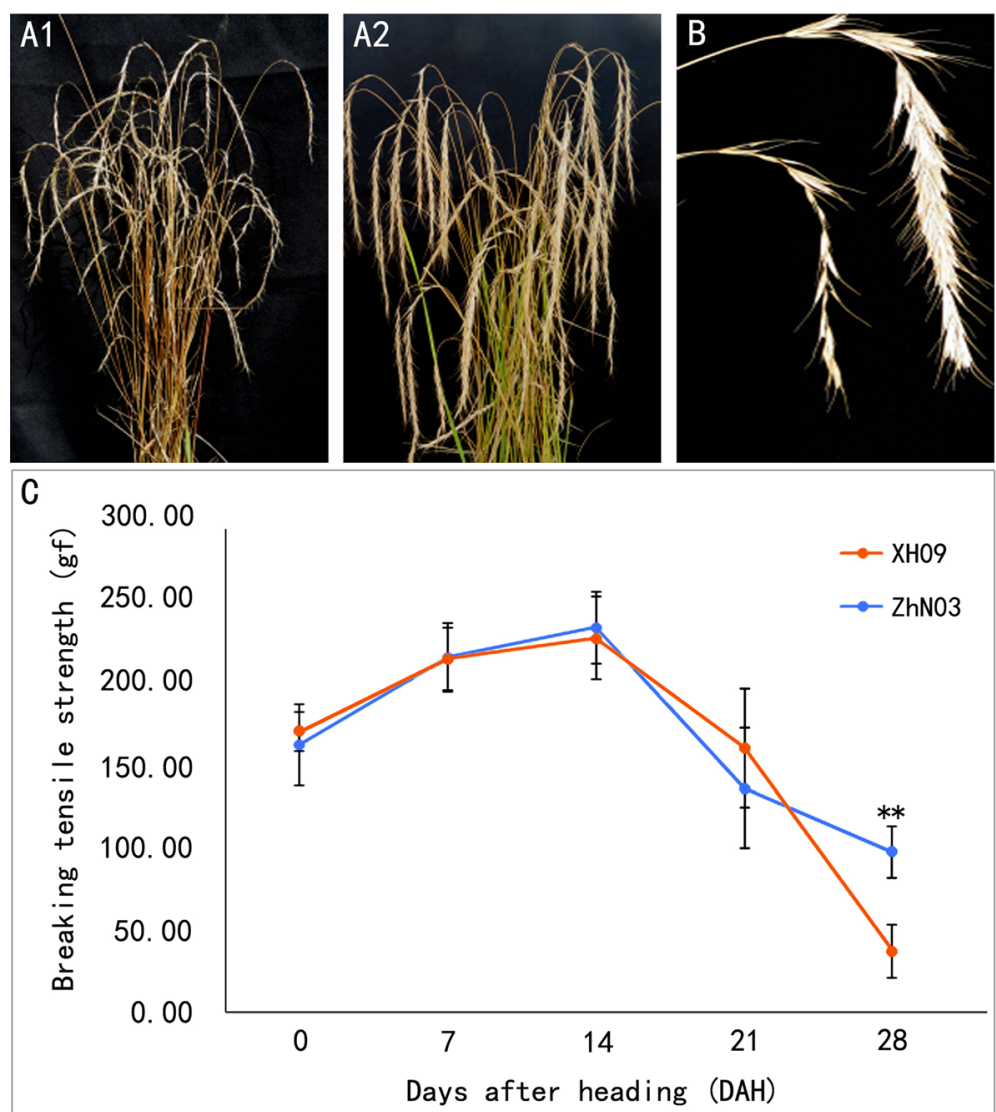

Fig. 1 Different seed shattering habits of two E. sibiricus genotypes. (a1) High seed shattering type XH09. (a2) Low seed shattering type ZhN03. (b) Seed shattering degree of inflorescence in XH09 and ZhN03. Photos taken at 28 days after heading. (c) Time-course changes in the seed shattering degree of XH09 and ZhN03 at 7, 14, 21 and 28 days after heading. BTS was measured upon detachment of seed from the pedicels by pulling. Bars indicate the mean values \pm standard deviation. Double asterisks $\left(^{* *}\right)$ represent significant difference of BTS between XH09 and ZhN03 at $p<0.01$ level

is conducted in the State Key Laboratory of Grassland Agro-ecosystems, Gansu, China. Samples were identified based on some important phenotypical characteristics such as plant height, inflorescence, leaf, stem and seed. This species is small-anthered and long-awned bunchgrass. They were selected and used in present study based on a previous screening for seed shattering in 28 E. sibiricus accessions [19]. The seeds of two genotypes were germinated in plastic boxes with moistened blotter paper at room temperature. After germination, seedlings were grown under greenhouse conditions until they were 8 weeks old. Then they were transplanted to the field plots in the experimental station at Lanzhou University, Yuzhong, Gansu, China (latitude $35^{\circ} 34^{\prime} \mathrm{N}$, longitude $103^{\circ}$ 34' E, elevation $1720 \mathrm{~m}$ ). No any permissions were required to carry out field experiment.

\section{Seed shattering phenotyping and histological analysis of pedicel structure}

The inflorescence of E. sibiricus is a spike containing 15-30 spikelets. Each spikelet consists of 5-8 normally developed florets with long awn (Fig. 1b). The level of seed shattering of $\mathrm{XH} 09$ and ZhN03 was determined by measuring the breaking tensile strength (BTS) required to detach the seeds from the pedicels [9]. Thirty randomly chosen spikelets of each plant were examined at each of the five developmental stages, 0, 7, 14, 21, 28 days after heading (DAH), and their average BTS values were calculated. Histological analysis of pedicel structure was carried out at the same five development stages concurrent with seed shattering measurements.

In order to reduce variation due to the spikelet position at each developmental stage, the three central spikelets of each florescence were used, and within each spikelet, the central florets were dissected together with a part of the rachilla [4]. The pedicels of each accession were fixed in solution 60: 5: 5: 30 ethanol: acetic acid: formalin: water solution and stored at $4{ }^{\circ} \mathrm{C}$ in $15 \mathrm{M}$ ethanol [4]. They were then dehydrated in a gradient of ethanol solutions (50, 70, 90 and 100\%) for $60 \mathrm{~min}$, respectively. After treatment with dimethylbenzene and a soaking in paraffin, tissue samples were sectioned 
longitudinally to a thickness of $8 \mu \mathrm{m}$, and stained for 3 min with Safranine-fast Green (Zhongtai, Shanghai, China). After staining, the pedicel structures were then observed under a Nikon Microphot FXA microscope (Nikon Corporation, Tokyo, Japan). Scanning electron microscopy was used to examine the pedicel junctions after detachment of seeds to detect the relationship between abscission layer development and seed shattering degree at each of the five developmental stages [2].

\section{Physiochemical analysis of the abscission zone}

The abscission zone tissues of the two genotypes (XH09, ZhN03) were harvested according to methods described by $\mathrm{Li}$ et al. [9]. The enzyme activity of two cell walldegrading enzymes (cellulase and polygalactouranase) was assayed in abscission zones of the two genotypes at the same five developmental stages used for BTS and histological analyses, following the manuscript's protocol of plant CE ELISA kit and plant PG ELISA kit, respectively.

\section{RNA extraction, cDNA library construction, and RNA-seq}

Abscission zone tissues of the two genotypes were collected at three of the five developmental stages: 7 days, 21 days and 28 days after heading (DAH). The three stages were selected based on results of seed shattering, histological and physiochemical analysis. According to our previous study, seed shattering was visible at 14 $\mathrm{DAH}$, transcriptome changes should start before this time point, therefore, 7 DAH was used as "zero time" before seed shattering related genes are activated. Each collected flower-pedicel structure consisted of an approximately $1-\mathrm{mm}$ region of the pedicel and $1.5 \mathrm{~mm}$ of the flower, which included the abscission zone $[9,22]$. Approximately $30 \mathrm{mg}$ of this abscission zone tissue was collected for each replicate. The test was carried out with three biological replicates. This material was immediately placed in liquid nitrogen and stored at $-80{ }^{\circ} \mathrm{C}$ for later RNA extraction. Total RNA from each tissue was extracted using Plant total RNA Kit (TIANGEN, Beijing, China) according to the manufacturer's instructions. RNA concentration and quality was measured using an Agilent 2100 Bioanalyzer (Agilent Technologies, Inc., Waldbronn, Germany). Total RNA samples were sent to Biomarker Technologies Corporation (Beijing, China) for cDNA library construction and transcriptome sequencing. Poly (A) mRNAs were enriched from the total RNA using magnetic oligo (dT) beads. RNA fragmentation, double-stranded cDNA synthesis, and PCR amplification were carried out according to the Illumina RNA-Seq protocol. Finally, sequencing of purified cDNA library were carried out on an Illumina GA- $\Pi$ (Illumina Inc., USA) using the Chrysalis 36 cycles v 3.0 sequencing kit, with one lane of $2 \times 101 \mathrm{bp}$ reads from both ends of the fragments ("paired ends") with 180 bp insert distance for assembly.

\section{De novo assembly, and annotation}

The clean reads were obtained after filtering adaptor sequences and reads with ambiguous ' $N$ ' bases and with a base quality less than Q30 using the FASTX toolkit. De novo transcriptome assembly of the quality reads was performed using the Trinity program [23]. Based on the Trinity assembly results, the unigene sequences were queried using BLASTX against the NCBI non-redundant protein sequence $(\mathrm{Nr})$, Annotated protein sequence database (Swiss-Prot), Gene Ontology (GO), Protein family (Pfam), euKaryotic Orthologous Groups (KOG), Kyoto Encyclopedia of Genes and Genomes (KEGG), and Cluster of Orthologous Groups (COG) databases (E-value $\leq 1 \mathrm{e}-5)$ to retrieve homology-based protein functional annotations. GO terms regarding the biological process, molecular function and cellular component were assigned to each sequence annotated using the Blast2GO software [24]. The WEGO software was used to plot the distribution of GO annotations of transcripts [25].

\section{Analysis of the functional enrichment of differentially expressed transcripts (DETs)}

Transcripts were mapped to the assembly using SOAPaligner, then the Fragments Per Kilobase per Million fragments mapped (FPKM) value for each transcript was measured according to methods described by Mortazavi et al. [26]. The transcript fold-change was calculated using the formula $\log _{2}$ (FC), and the correction for multiple tests used the false discovery rate (FDR) control method [27]. An absolute value of the $\log _{2}$ (FC) $\geq 2$ and FDR significance score $\leq 0.01$ were set as the thresholds to call significant DETs between two samples. STEM software was used to cluster the DETs with a $p \leq 0.05$ [28], and GO enrichment analysis and KEGG pathway enrichment analysis of the DETs were performed using agriGO [29] and KOBAS 2.0 [30], respectively.

\section{Validation of RNA-seq data by quantitative real-time PCR (qRT-PCR)}

A portion of total RNA used for the RNA-Seq analysis was used to make cDNA for qRT-PCR. qRT-PCR was conducted using the SYBR Premix Ex Taq ${ }^{\mathrm{TM}}$ II quantitative PCR system (Takara, Dalian), following the manufacturer's instructions, and reactions occurred on a Bio-Rad iQ5 real-time PCR instrument (Bio-Rad, Hercules, CA, USA). Based on the transcriptome results, ten candidate genes involved in seed shattering were selected for the qRT-PCR assays. Gene-specific primers were designed using Primer Express software (Applied Biosystems) and are shown in Additional file 1: Table S1. 
Expression levels of these DETs were calculated relative to reference gene GAPDH using the $2^{-\triangle \Delta \mathrm{Ct}}$ method [31]. All of the samples were tested in triplicate, and the experiments were performed on three biological replicates.

\section{Results}

\section{Time-course change in seed shattering degree of two} genotypes

The changes in the seed shattering degree of XH09 and ZhN03 were characterized over time by measuring pedicel breaking tensile strength (BTS), which is inversely proportional to shattering degree. During the first 14 days after heading (DAH), the BTS value did not differ between $\mathrm{XH} 09$ and $\mathrm{ZhN03}$ and were maintained at more than 150 gf (Fig. 1c). Significantly different BTS values were found between $\mathrm{XH} 09$ and $\mathrm{ZhN03}$ at 28 DAH. The BTS of ZhN03 began to decrease after 14 $\mathrm{DAH}$, but remained above 90 gf at $28 \mathrm{DAH}$. In comparison, the BTS value of XH09 decreased quickly after 14 $\mathrm{DAH}$, and dropped below $50 \mathrm{gf}$ at $28 \mathrm{DAH}$. The seeds of XH09 were easily threshed by hand crushing. Therefore, wild accessions ZhN03 and XH09 can be characterized as low - and high - seed shattering, respectively.

\section{Histological and physiochemical analysis of abscission zone}

Anatomical investigation with longitudinal sections indicated abscission layers were already present at heading in XH09 and ZhN03. They occurred on both sides of the vascular bundle, which could be stained dark red by safranine. The cells of the abscission layer were smaller than the parenchyma cells in the rachilla, and had an elliptic shape and an organized position. Degradation of the abscission layer was not observed in two genotypes by $14 \mathrm{DAH}$. Degradation of the abscission layer occurred in XH09 at 21 DAH (Fig. 2b), and broken abscission layer was found at $28 \mathrm{DAH}$ (Fig. 2c). In comparison, serious degradation of the abscission layer was not observed in ZhN03 at 21 (Fig. 2e) and 28 DAH (Fig. 2f). Early degradation of abscission layers was associated with the increased seed shattering in high seed shattering genotype XH09. Based on these staining results, there was less lignin in the abscission zone and surrounding pedicel tissues of XH09 (Fig. 2b) than in the ZhN03 (Fig. 2e). Additionally, scanning electron microscopy showed there was a smooth fracture surface on the rachilla in XH09 at 28 DAH (Fig. 2i, j) while in ZhN03 rough and irregular surface was observed, and cell structure was visible (Fig. $2 \mathrm{~m}, \mathrm{n}$ ).

To investigate how cell wall-degrading enzymes contribute to seed shattering, the changes of specific activity of cellulase (Fig. 3a) and polygalactouranase (Fig. 3b) were assayed in the abscission zone of XH09 and ZhN03. The two hydrolases exhibited a similar trend of activity at different stages in the growth and development of the seed. The mean specific activity of cellulase

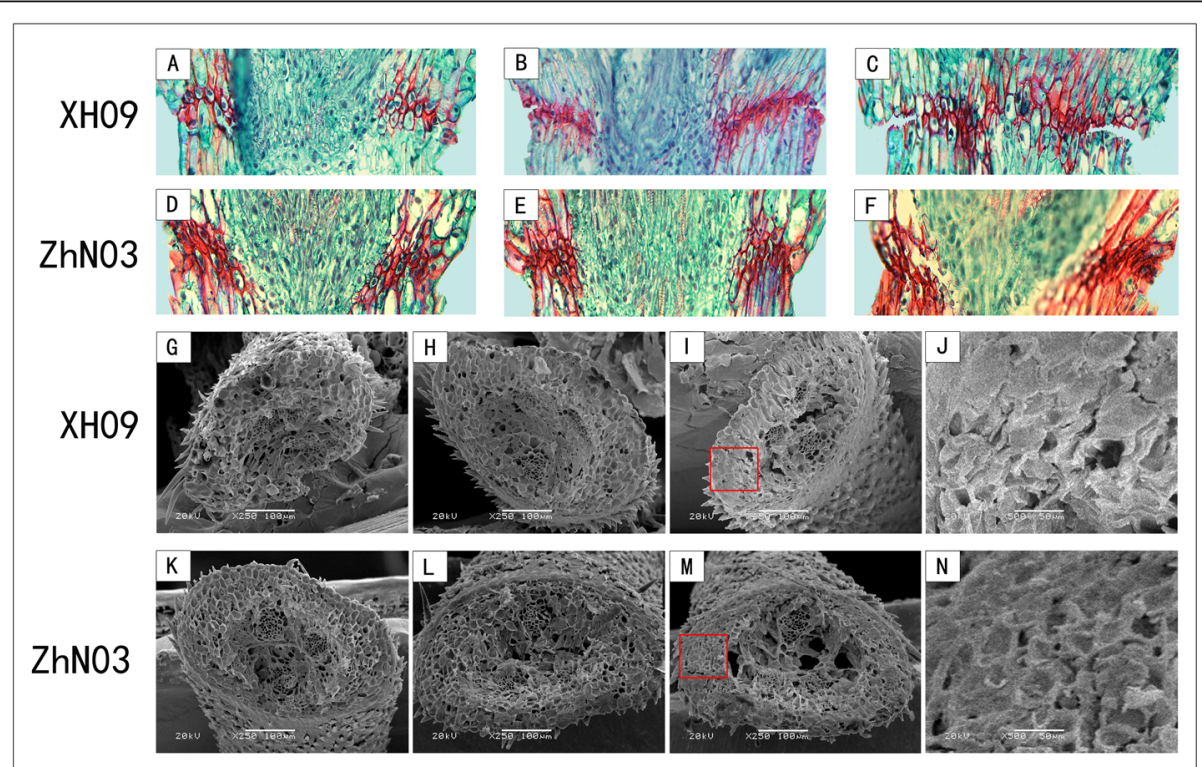

Fig. 2 Histological analysis of abscission zone. (a) and (d), (b) and (e), (c) and (f) show longitudinal sections across the abscission zone of XH09 and ZhN03 at 7 DAH, 21 DAH and 28 DAH, respectively. Sections were stained with safranine-fast green, and lignin in red. (g) and (k), (h) and (I), (i) and (m) show scanning electron microscopy photos of pedicel junction after detachment of seeds in XH09 and ZhN03 at 7 DAH, 21 DAH and 28DAH, respectively. (j) and (n) show close-up scanning electron microscopy photos corresponding to red boxes in (i) and (m). A peeled-off and smooth surface is observed in the high seed shattering genotype XH09 (j), whereas broken and rough surface is observed in the low seed shattering genotype ZhN03 (n) 


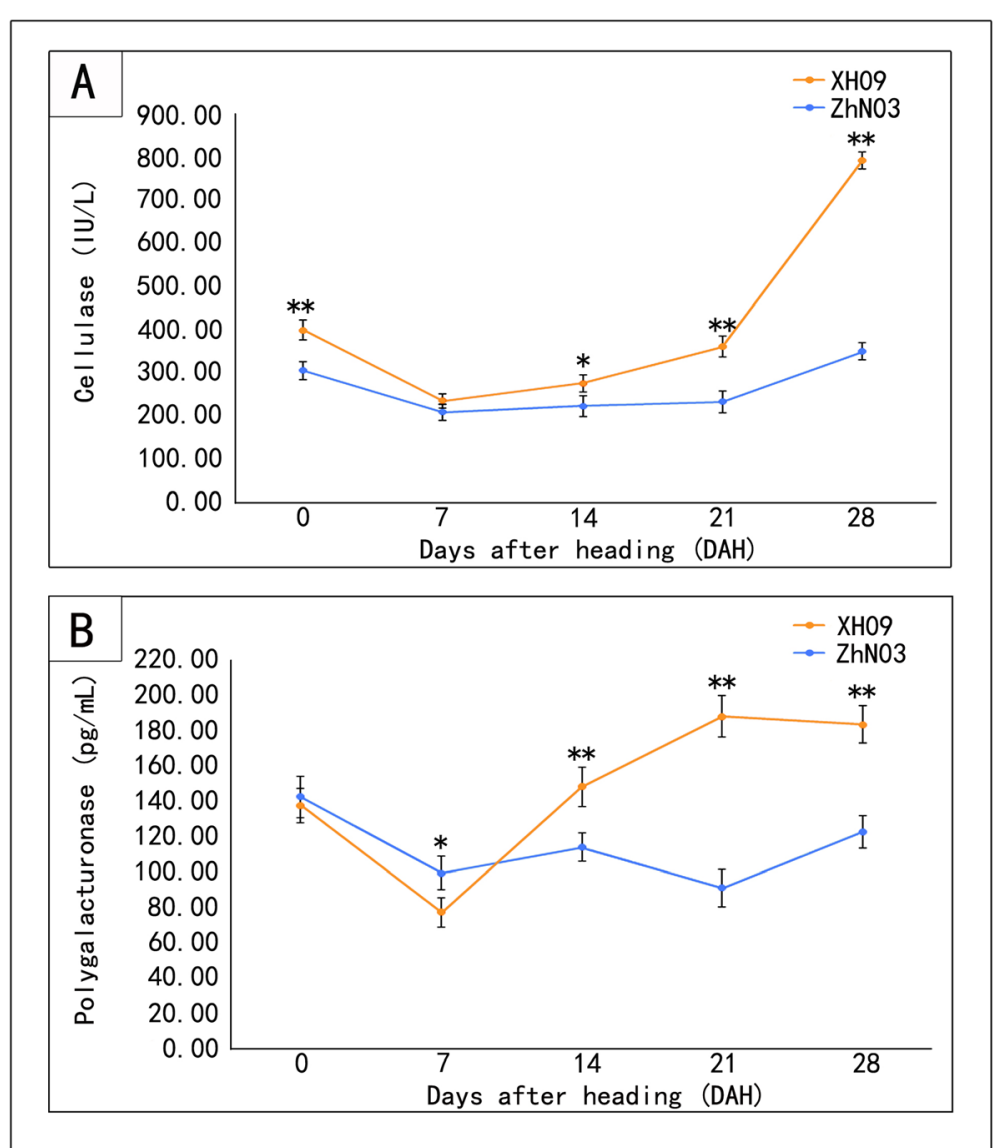

Fig. 3 Specific activity of two cell wall-degrading enzymes: cellulase (a) and polygalacturonase (b) in abscission zone. Bars indicate the mean values \pm standard deviation. Double asterisks $\left({ }^{*}\right)$ represent significant difference of enzyme activity between $\mathrm{XH} 09$ and ZhN03 at $p<0.01$ level

was higher in high seed shattering genotype XH09 (415.77 IU/L) than in low seed shattering genotype ZhN03 (266.8 IU/L). The activity of cellulase increased rapidly at $21 \mathrm{DAH}$ in $\mathrm{XH} 09$, and reached $796.38 \mathrm{IU} / \mathrm{L}$ at $28 \mathrm{DAH}$ while the activity of ZhN03 was $352.98 \mathrm{IU} / \mathrm{L}$ at $28 \mathrm{DAH}$. The mean specific activity of polygalactouranase was higher in XH09 $(149.35 \mathrm{pg} / \mathrm{ml})$ than in ZhN03 (115.73 pg/ml), especially at physiological maturity. At $28 \mathrm{DAH}$, polygalactouranase activity of $\mathrm{XH} 09$ was $186.50 \mathrm{pg} / \mathrm{ml}$ while the activity of ZhN03 was $124.77 \mathrm{pg} /$ $\mathrm{ml}$. Physiochemical analysis revealed significantly different cell wall-degrading enzymes activity in the abscission zone between XH09 and ZhN03 at 21DAH and 28DAH.

\section{Transcriptome sequencing revealed differentially expressed transcripts in abscission zone}

To dissect the molecular mechanism and explore the putative genes related to seed shattering in E. sibiricus. cDNA libraries were constructed from abscission zone tissue RNA samples, and sequenced using an Illumina HiSeq $^{\text {Ta }} 2500$ platform. These Illumina data are available in the Sequence Reads Archive (SRA) with accession number SRX2617497. After cleaning and checking the read quality, high quality reads were assembled using Trinity software. The number of sequences ranged from 12.2 - 17.0 million reads per sample (Table 1). A total of 185,523 unigenes were identified, of which 86,634 unigenes were annotated in at least one database (Table 2 ). The expression abundance of each sample was measured. More than 30,000 differentially expressed transcripts (DETs) were detected among E. sibiricus libraries at three developmental stages: 7 days, 21 days and 28 days after heading, of which 1171 (476 up-regulated, 695 down-regulated), 4421 (1151 up-regulated, 2910 down-regulated), 1878 (431 up-regulated, 1447 downregulated) were predicted from "XH09-7 vs ZhN03-7", "XH09-21 vs ZhN03-21", "XH09-28 vs ZhN03-28", respectively (Table 3).

These DETs were searched against the GO database to categorize standardize gene function. A total of 2589 DETs were assigned to three main GO categories (cellular component, biological process and molecular function) and 53 subcategories (Additional file 2: Figure S1). In the cellular component category, "cell part", "organelle", and 
Table 1 Summary of the sequence data analysis

\begin{tabular}{|c|c|c|c|c|}
\hline Sample & Total clean reads & Total clean nucleotides (bp) & GC\% & $\geq Q 30(\%)$ \\
\hline XH09-7-1 & $14,651,268$ & $3,843,213,534$ & 54.75 & 87.35 \\
\hline XH09-7-2 & $15,688,899$ & $3,769,876,457$ & 55.56 & 88.41 \\
\hline XH09-7-3 & $15,102,813$ & $3,809,312,291$ & 55.14 & 88.23 \\
\hline XH09-21-1 & $15,655,278$ & $3,944,283,732$ & 55.76 & 88.45 \\
\hline XH09-21-2 & $15,478,709$ & $3,899,896,658$ & 55.46 & 88.61 \\
\hline XH09-21-3 & $15,122,910$ & $3,810,402,251$ & 55.17 & 88.35 \\
\hline XH09-28-1 & $14,728,212$ & $3,710,976,309$ & 57.68 & 88.03 \\
\hline $\mathrm{XH} 09-28-2$ & $14,400,350$ & $3,628,304,803$ & 57.24 & 88.17 \\
\hline XH09-28-3 & $14,879,668$ & $3,749,135,994$ & 55.56 & 88.26 \\
\hline ZhN03-7-1 & $14,439,791$ & $3,822,708,203$ & 54.61 & 88.57 \\
\hline ZhN03-7-2 & $13,549,381$ & $3,410,137,265$ & 53.86 & 88.48 \\
\hline ZhN03-7-3 & $13,403,148$ & $3,447,463,715$ & 54.14 & 88.54 \\
\hline ZhN03-21-1 & $15,529,892$ & $3,912,968,243$ & 53.71 & 88.59 \\
\hline ZhN03-21-2 & $13,494,783$ & $3,400,148,238$ & 54.36 & 88.58 \\
\hline ZhN03-21-3 & $13,353,208$ & $3,364,473,812$ & 54.17 & 88.64 \\
\hline ZhN03-28-1 & $12,247,393$ & $3,085,813,765$ & 57.48 & 88.67 \\
\hline ZhN03-28-2 & $13,062,771$ & $3,291,238,868$ & 56.90 & 88.73 \\
\hline ZhN03-28-3 & $17,028,238$ & $4,290,493,634$ & 57.88 & 88.45 \\
\hline
\end{tabular}

"membrane" were dominant groups. In the biological process category, "metabolic process", "cellular process" and "single-organism process" were dominant groups. In the molecular function category, "catalytic activity", "binding" and "transporter activity" were the dominant categories. To reveal the significantly enriched GO terms in the DETs, a GO enrichment analysis of the functional significance was performed via the agriGO website. 11, 70, 51 significantly enriched GO terms were found in "XH09-7 vs ZhN03-7", "XH09-21 vs ZhN03-21", "XH09-28 vs ZhN03-28”, respectively (Additional file 3: Table S2).

To characterize the complex biological behaviors of the transcriptome, all the DETs from three differentially expressed transcript sets were also subjected to a KEGG pathway enrichment analysis. In total, 1318 DETs could be annotated and assigned to KEGG pathway, of which 107, 512, 699 DETs were found in "XH09-7 vs ZhN037", "XH09-21 vs ZhN03-21", "XH09-28 vs ZhN03-28", respectively (Additional file 4: Figure S2). The most representive pathway found included "ribosome (Ko03010)", "carbon metabolism (ko01200)", "apoptosis (Ko4210), "protein processing in endoplasmic reticulum (Ko04141)", and so on. In this study we mainly focused on "peroxisome (Ko04146)", "phenylpropaniod biosynthesis (Ko00940)", "plant hormone signal transduction (Ko4075)". Overall, in the pathway of "phenylpropaniod biosynthesis" (Additional file 5: Figure S3), 59 unigenes were annotated and encoded 12 putative enzymes involved in lignin biosynthesis. In the pathway of "plant hormone signal transduction" (Additional file 6: Figure S4),

Table 2 BLAST analysis of the non-redundant unigenes against public databases

\begin{tabular}{llll}
\hline Annotated database & Number of Unigene & $300 \leq$ length $<1000$ & length $\geq 1000$ \\
\hline Nr annotation & 65,838 & 35,264 & 30,574 \\
GO annotation & 44,054 & 20,100 & 23,954 \\
Pfam annotation & 42,613 & 15,787 & 26,826 \\
KOG annotation & 35,924 & 13,211 & 22,713 \\
SwissProt annotation & 44,012 & 21,214 & 22,798 \\
KEGG annotation & 23,362 & 10,468 & 12,894 \\
COG annotation & 23,512 & 9127 & 14,385 \\
All annotated & 86,634 & 45,380 & 41,254 \\
\hline
\end{tabular}


Table 3 Statistical table of differently expressed transcripts (DETs), with annotation

\begin{tabular}{llll}
\hline Type & XH09-7 vs ZhN03-7 & XH09-21 vs ZhN03-21 & XH09-28 vs ZhN03-28 \\
\hline num & 1171 & 4421 & 1878 \\
up & 476 & 1151 & 431 \\
down & 695 & 2910 & 1447 \\
COG & 52 & 766 & 454 \\
GO & 181 & 1837 & 571 \\
KEGG & 74 & 810 & 544 \\
KOG & 135 & 1249 & 763 \\
Pfam & 222 & 1958 & 951 \\
SwissPort & 167 & 1692 & 657 \\
nr & 435 & 2932 & 1109 \\
all annotated & 544 & 2974 & 1231 \\
\hline
\end{tabular}

54 unigenes were differentially expressed, of which 7 were involved in ethylene biosynthesis and regulation, 10 for abscisic acid, and 17 for auxin (Table 4).

\section{Comparative transcriptome analysis revealed candidate transcripts involved in seed shattering}

Seed shattering measurement and physiochemical analysis revealed significantly different BTS values and cell wall-degrading enzymes activity in the abscission zone between XH09 and ZhN03 at 21 DAH and 28 DAH. To identify candidate genes for seed shattering, we compared the DETs in both genotypes at the three time points: $7 \mathrm{DAH}, 21 \mathrm{DAH}$ and $28 \mathrm{DAH}$. A total of 7470 DETs were detected at three developmental stages, of which 1171 DETs were predicted from "Xh09-7 vs ZhN03-7" and more DETs were predicted from "Xh0921 vs ZhN03-21" and "Xh09-28 vs ZhN03-28". Based on the annotation, we further selected 18, 138 and 97 putative genes in response to seed shattering from "XH09-7 vs ZhN03-7", "XH09-21 vs ZhN03-21" and "XH09-28 vs ZhN03-28", respectively (Additional file 7: Table S3). From the putative function of these DETs, we found 5 major function group: cell wall hydrolysis or modification, hydrolase activity, phytohormone signaling and response, transcription factor, and protein kinase activity. Eight candidate DETs involved in peroxidase activity (c60174.graph_c0), hydrolase activity (c72047.graph_c1, c30667.graph_c0, c54680.graph_c1,), ethylene-responsive transcription factor (c23015.graph_c0,), and wallassociated receptor kinase (c34865.graph_c0, c4232 9.graph_c0, c68413.graph_c0) were found at all the three developmental stages. A total of 58 DETs involved in hydrolase activity were predicted from "XH09-21 vs ZhN03-21", of which 13, 2 and 12 genes involved in glucosidase activity, polygalacturonase activity and xylanase inhibitor were differentially expressed in the abscission zone of XH09 and ZhN03, respectively (Fig. 4). In particular, two genes involved in polygalacturonase activity were down-regulated in low seed shattering genotype ZhN03 compared to high seed shattering genotype XH09. In "XH09-28 vs ZhN03-28”, 18 of 97 genes were up-regulated in the abscission zone of the low seed shattering genotype ZhN03. In particular, a xylanase inhibitor protein $(X I P)$ gene was expressed in the abscission zone, and an ethylene responsive transcription factor and an ethylene receptor gene (EIN4) involved in phytohormone signaling was up-regulated in $\mathrm{ZhN03}$ at 28 DAH compared to high seed shattering genotype XH09.

\section{RNA-seq expression validation by quantitative reverse transcription PCR (qRT-PCR)}

To quantitatively determine the reliability of our transcriptome data, ten transcripts involved in activation of abscission were selected for qRT-PCR validation. These candidates included phenylalanine ammonia-lyase $(P A L)$, beta-glucosidase $(G L U)$, caffeoyl-CoA O-methyl transferase (CCOAOMT), peroxidase $(P O X)$, serine/ threonine-protein kinase SRK2 (SnRK2), ethylene receptor $(E T R)$, catalase $(C A T)$, Endoglucanase $(E G L)$, xylanase inhibitor protein 1 (XIP1) and cellulose synthase (CesA). The results showed that all ten transcripts were expressed in the $\mathrm{AZ}$ at three development stages, 7 days, 21 day and 28 days after heading. We used XH09-7 as a benchmark for relative expression analysis. CCOAOMT and CesA were down-regulated in $\mathrm{XH} 09$ and ZhN03 at 21DAH and $28 \mathrm{DAH}$. The expression of other 8 transcripts was up-regulated in ZhN03-28 (Fig. 5). The relative expression of XIP1 for ZhN03-28 was almost 120 times higher than that of XH09-07. Six genes (GLU, $P O X, E G L, C A T, E T R$ and SnRK2) were differentially expressed in ZhN03-21 and ZhN-28 in comparison of the high-seed shattering genotype XH09. A linear regression analysis of the fold-change in expression measured via RNA-seq vs qRT-PCR displayed a positive correlation $(r=0.76, P<0.05)$. 
Table 4 Candidate genes enriched in phenylpropanoid biosynthesis and plant hormone signal transduction pathway

\begin{tabular}{|c|c|c|c|c|c|c|c|}
\hline KEGG pathway & Gene & Definition & KO id & EC no. & No.All & No.Up & No.Down ${ }^{c}$ \\
\hline \multicolumn{8}{|c|}{ Plant hormone signal transduction } \\
\hline \multirow[t]{3}{*}{ Abscisic acid } & PP2C & protein phosphatase $2 \mathrm{C}$ & K14497 & 3.1.3.16 & 5 & 4 & 1 \\
\hline & SRK2 & serine/threonine-protein kinase & K14498 & 2.7.11.1 & 2 & 2 & 0 \\
\hline & $\mathrm{ABF}$ & ABA responsive element binding factor & K14432 & & 3 & 1 & 2 \\
\hline \multirow[t]{3}{*}{ Ethylene } & ETR & ethylene receptor & K14509 & 2.7.13.- & 2 & 2 & 0 \\
\hline & EIN2 & ethylene-insensitive protein 2 & K14513 & & 3 & 2 & 1 \\
\hline & EIN3 & ethylene-insensitive protein 3 & K14524 & & 2 & 2 & 0 \\
\hline \multirow[t]{5}{*}{ Auxin } & $A \cup X 1$ & auxin influx carrier & K13946 & & 1 & 0 & 1 \\
\hline & IAA & auxin-responsive protein IAA & K14484 & & 6 & 1 & 5 \\
\hline & ARF & auxin response factor & K14486 & & 2 & 1 & 1 \\
\hline & $\mathrm{GH} 3$ & auxin responsive $\mathrm{GH} 3$ gene family & K14487 & & 2 & 0 & 2 \\
\hline & SAUR & SAUR family protein & K14488 & & 6 & 1 & 5 \\
\hline \multirow[t]{4}{*}{ Cytokinine } & CRE1 & arabidopsis histidine kinase $2 / 3 / 4$ & K14489 & EC:2.7.13.3 & 1 & 0 & 1 \\
\hline & AHP & histidine-containing phosphotransfer peotein & K14490 & & 1 & 1 & 0 \\
\hline & B-ARR & two-component response regulator ARR-B family & K14491 & & 3 & 0 & 3 \\
\hline & ARR-A & two-component response regulator ARR-B family & K14492 & & 3 & 0 & 3 \\
\hline Gibberellin & TF & phytochrome-interacting factor 4 & K16189 & & 1 & 0 & 1 \\
\hline \multirow[t]{2}{*}{ Brassinosteroid } & BRI1 & protein brassinosteroid insensitive 1 & K13415 & EC:2.7.10.1 & 1 & 0 & 1 \\
\hline & BSK & BR-signaling kinase & K14500 & EC:2.7.11.1 & 1 & 1 & 0 \\
\hline \multirow[t]{2}{*}{ Jasmonic acid } & COl1 & coronatine-insensitive protein 1 & K13463 & & 1 & 0 & 1 \\
\hline & $J A Z$ & jasmonate ZIM domain-containing protein & K13464 & & 2 & 0 & 2 \\
\hline \multirow[t]{2}{*}{ Salicylic acid } & NPR1 & regulatory protein NPR1 & K14508 & & 3 & 1 & 2 \\
\hline & TGA & transcription factor TGA & K14431 & & 3 & 0 & 3 \\
\hline \multirow{12}{*}{$\begin{array}{l}\text { Phenylpropanoid } \\
\text { biosynthesis }\end{array}$} & PAL & phenylalanine ammonia-lyase & K10775 & 4.3.1.24 & 5 & 0 & 5 \\
\hline & $4 C L$ & 4-coumarate-CoA ligase & K01904 & 6.2.1.12 & 4 & 0 & 4 \\
\hline & $\mathrm{P} / \mathrm{TAL}$ & phenylalanine/tyrosine ammonia-lyase & K13064 & 4.3.1.25 & 1 & 0 & 1 \\
\hline & $\mathrm{F} 5 \mathrm{H}$ & ferulate-5-hydroxylase & K09755 & 1.14.-- & 1 & 0 & 1 \\
\hline & CCoa-OMT & caffeoyl-CoA O-methyltransferase & K00588 & 2.1.1.104 & 2 & 0 & 2 \\
\hline & CALDH & coniferyl-aldehyde dehydrogenase & K12355 & 1.2.1.68 & 1 & 0 & 1 \\
\hline & BGLU & beta-glucosidase & K01188 & 3.2.1.21 & 8 & 3 & 5 \\
\hline & $C C R$ & cinnamoyl-CoA reductase & K09753 & 1.2.1.44 & 3 & 2 & 1 \\
\hline & CAD & cinnamyl-alcohol dehydrogenase & K00083 & 1.1.1.195 & 5 & 2 & 3 \\
\hline & POX & peroxidase & K00430 & 1.11.1.7 & 21 & 6 & 15 \\
\hline & $\mathrm{SOH}$ & shikimate O-hydroxycinnamoyltransferase & K13065 & 2.3.1.133 & 6 & 2 & 4 \\
\hline & $\mathrm{C}^{\prime} \mathrm{H}$ & Coumaroylquinate (coumaroylshikimate) 3'-monooxygenase & K09754 & 1.14.13.36 & 2 & 1 & 1 \\
\hline
\end{tabular}

the total number of uni-transcripts analysed

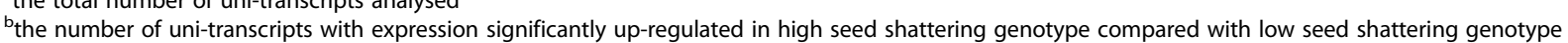

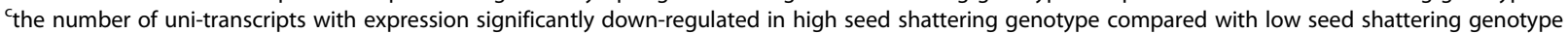

\section{Discussion}

\section{Histological and physiochemical difference of abscission zone}

Shedding of leaves, fruit and seeds is a complex and highly coordinated process involving multiple changes in cell structure, metabolism and gene expression [32]. To elucidate the mechanism responsible for abscission in E. sibiricus in the present study, we conducted a combination of morphological, histological, physiochemical and transcriptome analysis in two genotypes (XH09 and ZhN03) with contrasting seed shattering phenotypes. The results showed that the high seed shattering genotype XH09 had a lower BTS value (36.73 gf) at seed physiological maturity when compared to low seed shattering genotype ZhN03 (96.3 gf). 


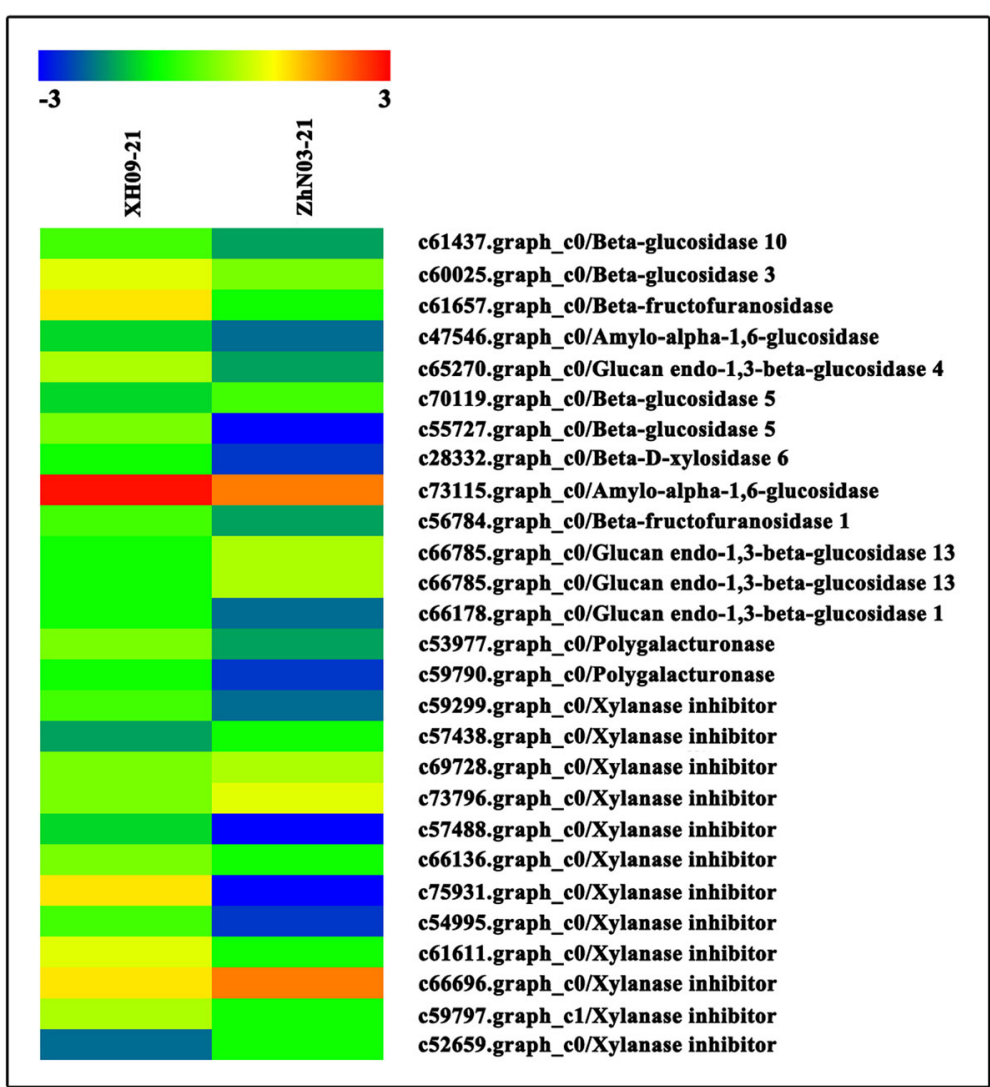

Fig. 4 Heat map diagram of the expression levels of 27 differentially expressed transcripts (DETs) involved hydrolase activity. The DETs were found between high seed shattering genotype XH09 and low seed shattering genotype ZhN03 at 21 days after heading

Histological analysis of abscission zone showed a smooth fracture surface of rachilla in XH09, suggesting the higher level of degradation. This may resulted from the increased cellulase and polygalacturonase activity found in abscission zone of XH09. In several systems, abscission is related to cleavage and degradation of cell wall components by cell wall hydrolytic enzymes including cellulase and polygalacturonase; and the activity of cellulase is associated with many processes of plant growth and development, such as fruit ripening and organ abscission [33]. A correlation between increasing polygalacturonase activity and cell separation was reported in plant organs [34], such that abscission-specific polygalacturonase might play an important role in breaking down the pectin rich middle lamella during the abscission process that leads to separation [32]. Our results indicated the involvement and role of cellulase and polygalacturonase in seed shattering.

\section{Cell wall hydrolysis related genes}

The plant cell wall is mainly composed of non-starch polysaccharides, including cellulose and hemicellulose [35]. Cellulase $(1,4,-\beta$ - glucanase $)$ is the first enzyme reported to contribute to wall loosening during abscission [36]. Our KEGG pathway enrichment analysis of the
DETs indicated 28 unigenes involved in cellulase activity. Most of these unigenes were up-regulated in the abscission zone of both genotypes at 28 days after heading. These results indicated that higher expression of these unigenes might lead to an increase in seed shattering at seed physiological maturity. Many plant cellulase genes belong to a glycosyl hydrolase family that modify cell wall structure and component during tissue development $[37,38]$. In rice, the gene OsCel9D (synonym OsGLU1), encoding an endo- $1,4,-\beta$ - glucanase gene with cellulose function, is related to the cell wall components in rice; and OsCel9D mutations reduce cell elongation and cellulose content, and increase the pectin content, therefore hampering the abscission process in seed shattering [38]. The relative expression of an endo-1,4$\beta$-glucanase gene in rice was found to be associated with seed shattering [39]. During the abscission of leaves, flowers and seeds, increased expression of endo-1,4- $\beta$ glucanase gene could facilitate natural separation of plant organs [40-42].

Xylan is the major component of hemicelluloses. Xylanase can catalyze the hydrolysis of the $\beta$-1,4-xylosidic bonds in xylan, the activity of xylanase can be inhibited by xylanase inhibitors (XIs) [35]. Xylanases have been 


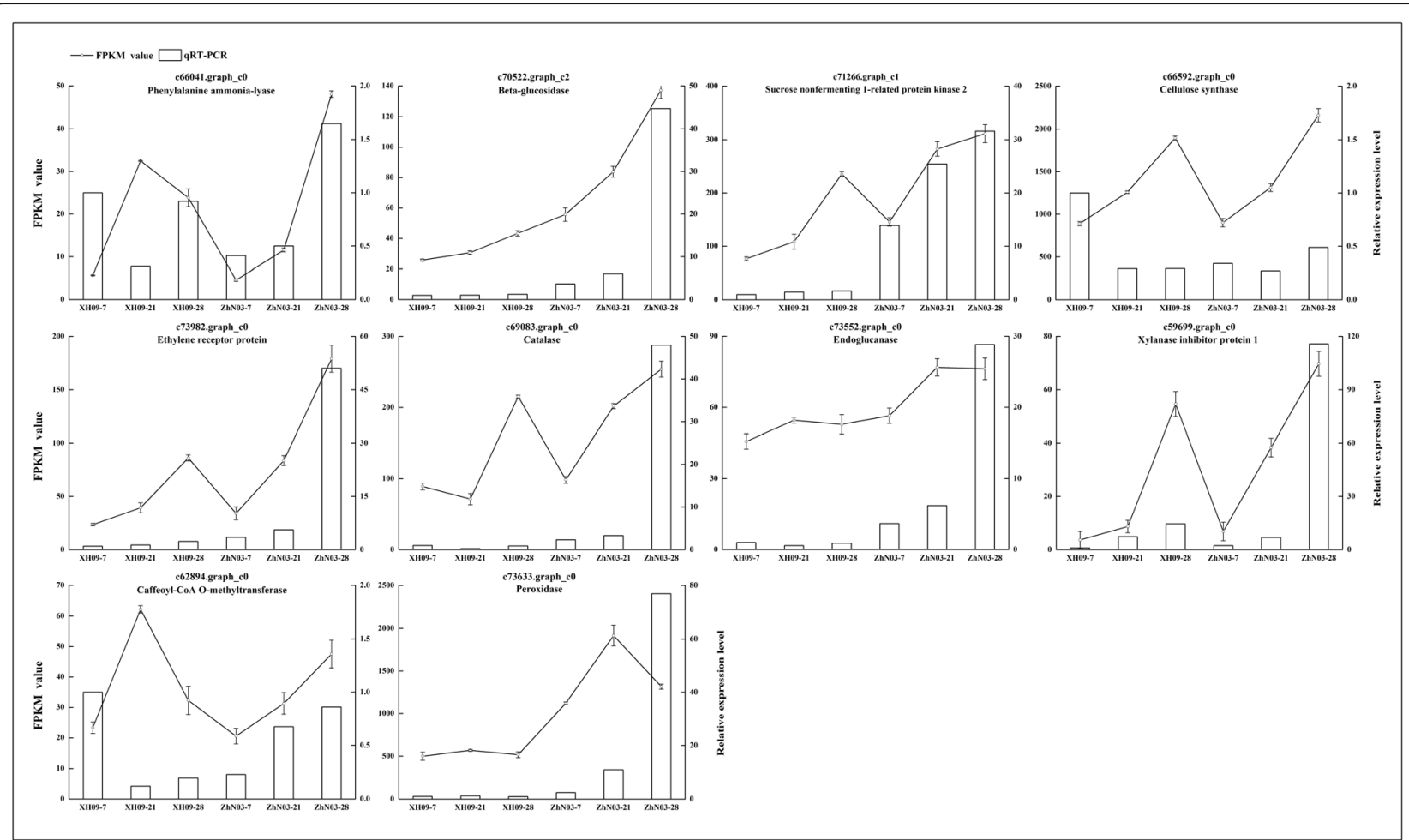

Fig. 5 qRT-PCR validations of RNA-seq data. Expression profiles of the selected genes as determined by RNA-seq and qRT-PCR. Data were collected from high seed shattering genotype XH09 and low seed shattering genotype ZhN03 at 7, 21 and 28 days after heading. The left-hand $\mathrm{y}$-axis indicates FPKM value. The right-hand $\mathrm{y}$-axis indicates relative expression level. Bars indicate the mean values \pm standard deviation

reported to play an important role in plant defense against pathogens [43] and herbivores [35]. However, whether xylanases are also involved in seed shattering remains largely unknown. In rice, at least three XIP type xylanase inhibitor genes (rice XIP, RIXI and OsXIP) have been reported, and these genes are differentially induced by stress [44-46]. In the present study, 12 XIP genes were differently expressed in the $\mathrm{AZ}$ of both genotypes at 21 DAH (Fig. 4), and the low shattering genotype ZhN03 showed much higher expression of these genes when compared with high shattering genotype XH09. This indicates that this gene might have an effect on seed shattering in the evaluated genotypes, and the expression of this gene is associated with a reduction of seed shattering.

\section{Plant hormone-related genes}

Plant hormones, also known as phytohormones, are signal molecules produced within the plant that have an important role in regulating a wide range of plant growth and development processes, including abscission. Our KEGG pathway enrichment analysis of the DETs indicated 54 unigenes involved in plant hormone signal transduction, of which 17 were related to Auxin, 8 to Cytokinine, 1 to Gibberellin, 10 to Abscisic acid, 7 to Ethylene, 2 to Brassinosteroid, 3 to Jasmonic acid, and 6 to Salicylic acid response pathways. Abscisic acid, ethylene, and auxin are important plant growth regulators in regulating abscission [32, 47]. Abscisic acid plays a direct role in abscission of organs such as seeds [48]. Abscisic acid signal transduction is regulated by several groups of ABA-responsive genes such as an ABA receptor PYR/ $P Y L$, a type $2 \mathrm{C}$ protein phosphatase $(P P 2 C)$, a serine/ threonine protein kinase $(S n R K 2)$ and an ABRE-binding factor $(A B F)$ [49-51]. Previous studies have shown that PP2Cs are negative regulators of ABA signaling [49]. On the other hand, $S n R K 2$ positively regulate ABA responses [50], but its activity can be inhibited by $P P 2 C$. In the presence of ABA, the interaction between the $P P 2 C s$ and SnRK2s can be disturbed by the $P Y R / P Y L$ receptor, thus preventing the $P P 2 C$-mediated dephosphorylation of $S n R K 2$, causing the activation of $S n R K 2$ kinases [51]. In the present study, we found four of the five $P P 2 C$ genes up-regulated, two $S n R K 2$ genes up-regulated, and one of two identified $A B F$ genes up-regulated in the abscission zone of the low seed shattering genotype. Our results suggest the interaction of these ABA-responsive genes may have contributed to seed shattering.

Ethylene is an important plant hormone also known to regulate flower and seed abscission, and elevation in ethylene production is commonly associated with tissue senescence and cell stress [52]. In the present study, we found that 6 ethylene-responsive genes (2 ETR genes, 2 
EIN2 gene and 2EIN3 genes) were up-regulated in abscission zone of low seed shattering genotype. Several homologs of these genes have been involved in senescence in Arabidopsis and tomato, including ETR1 [53] and its homologous genes eTAEl [54], LeETR1 and LeETR2 [55], ERS [56, 57], and EIN3/EIL [58]. The ethylene insensitive mutant of Arabidopsis etr1 exhibited a delay in the shedding of floral parts, suggesting the roles in regulating the timing of abscission.

As with ethylene responses, many genes required for normal auxin signaling have been identified, including $A U X / I A A$, the small auxin up RNA (SAUR), and gretchehagen-3 (GH3) [59]. In this study, three IAA responsive genes (1SAUR, $1 A R F$, and $1 A U X / I A A)$ were up-regulated in the abscission zone of our low seed shattering genotype. In rice, overexpression of a SAUR gene caused reductions in root and shoot growth and development, indicating it functions as a negative regulator of auxin synthesis and transport [60]. GH3, as a negative feedback regulator of IAA concentration, can help maintain auxin homeostasis [61]. Additionally, ethylene is a potent inhibitor of auxin while the auxin level of the abscission zone significantly affects the sensitivity to ethylene [32]. A balance and interaction between ethylene and auxin (IAA) may be the key factor that regulates and determine the timing of the abscission process.

\section{Lignin biosynthesis related genes in the $A Z$ are putative seed shattering genes}

Lignin is a complex phenylpropanoid polymer, fills the spaces between cell wall polysaccharides, and confers mechanical strength to the cell wall [62]. It is identified as a major factor in the recalcitrance of cell walls to digestion, particularly during enzymatic hydrolysis [63]. A previous study in rice showed that seed shattering can be induced by inhibiting lignin biosynthesis, where overexpression of the BEL1-type homeobox gene SH5 in the non-shattering "IIpum" variety led to an increase in seed shattering because lignin levels were decreased in the abscission zone and surrounding pedicel tissues [64]. In present study, staining of pedicels at 21 days and 28 days after heading showed that lignin deposition was much lower in XH09 than in ZhN03. Meanwhile, XH09 had lower BTS value when compared with ZhN03. These results implied high seed shattering degree of XH09 may be due to a reduction of lignin content. At least ten enzymes are required for monolignol biosynthesis: phenylalanine ammonia-lyase $(P A L)$, cinnamic acid 4hydroxylase $(C 4 H)$, cinnamyl-alcohol dehydrogenase $(C A D)$, cinnamoyl-CoA reductase $(C C R)$, caffeic acid/5-hydroxyfe rulic acid $O$-methyltransferase (CoMT), caffeoyl-CoA Omethyltransferase (CCOAOMT), coniferaldehyde dehydro genase $(C A L D H), p$-coumarate: CoA ligase $(4 C L)$, ferula 5 hydroxylase $(F 5 H)$ and shikimate O-hydroxycinnamoy transferase $(H C T)$ [65]. Generally, suppression of genes early in the monolignol biosynthetic pathway, such as $P A L, C 4 H$, $H C T$ and $C 3^{\prime} H$, significantly reduce lignin content $[63,66]$. A similar result was found in this study, where $P A L$ was downregulated and lignin content was lower in low seed shattering genotype XH09, corresponding to increased seed shattering. Changes in the expression level of other monolignol biosynthesis genes affect the amount of lignin and lignin composition $[62,67,68]$. In the present study, two $C A D$ genes were down-regulated in XH09. Expression of genes in the monolignol biosynthetic pathway can also be regulated by many transcription factors with a MYB DNA binding domain [69, 70]. We found two transcription factors with MYB-like DNA binding domains that were differently expressed in XH09 and ZhN03 at seed physical maturity; one was upregulated in $\mathrm{ZhN03}$ while the other was down-regulated. These results indicated that the different expression patterns of these identified DETs may resulted in the difference of lignin content in abscission zone and surrounding pedicel tissues, that may affect the seed shattering degree of XH09 and ZhN03.

\section{Conclusions}

Seed shattering of E. sibiricus is caused by a degradation of the abscission layer formed at the basal part of grains. High seed shattering genotype $\mathrm{XH} 09$ had higher activity of cellulase and polygalacturonase in the abscission zone. In present study more than 30,000 DETs were detected among the E. sibiricus libraries, of which 7.470 DETs were predicted from "XH09-7 vs ZhN03-7", "XH09-21 vs ZhN0321 " and "XH09-28 vs ZhN03-28". Many genes that involved in cell wall-degrading enzymes, lignin biosynthesis, and plant hormones (e.g. ethylene, auxin and abscission acid) were differentially transcribed. The expression of some genes (e.g., $P A L, A B F, X I P$ and $E G L)$ were associated with reduction of seed shattering, but which genes played a key role in difference of seed shattering still remains unknown. These transcripts provide hypotheses for further testing and development of low-shatter E. sibiricus germplasm. This study provided novel insights into the mechanism of seed shattering in E. sibiricus.

\section{Additional files}

\section{Additional file 1: Table S1. Primers used for $q R T-P C R$ analysis.} (XLS $22 \mathrm{~kb}$ )

Additional file 2: Figure S1. GO classification results of differentially expressed transcripts (DETs) found in three DETs sets. The genes were assigned to three main categories: cellular component, molecular function and biological process. The right-hand $y$-axis indicates the number of annotated genes. The left-hand $y$-axis indicates the percentage of annotated genes. (PDF 617 kb)

Additional file 3: Table S2. Significantly-enriched GO terms found in three differentially expressed transcript sets. (XLS 49 kb) 
Additional file 4: Figure S2. KEGG classification results of differentially expressed transcripts (DETs) found in three DETs sets. All DETs were assigned to five categories: cellular process, environmental information processing, genetic information processing, metabolism and organismal systems. (PDF $182 \mathrm{~kb}$ )

Additional file 5: Figure S3. Differentially expressed transcripts involved in the monolignol biosynthesis. Green means that the DETs were down regulated, red represents up regulated, and blue indicates that genes were of mixed expression patterns in the low seed shattering genotype compared to the high seed shattering genotype. (PDF $67 \mathrm{~kb}$ )

Additional file 6: Figure S4. Differentially expressed transcripts involved in plant hormone signal transduction pathway. Green means that the DETs were down regulated, red represents up regulated, and blue indicates that genes were of mixed expression patterns in the low seed shattering genotype compared to the high seed shattering genotype. The diagram of network was cited from KEGG website. (PDF $176 \mathrm{~kb}$ )

Additional file 7: Table S3. Differentially expressed transcripts related to seed shattering found in three DETs sets at three time points. (XLS $567 \mathrm{~kb})$

\section{Abbreviations}

AZ: Abscission zone; BTS: Breaking tensile strength; CE: Cellulase; COG: Cluster of orthologous group; DAH: Days after heading:

DET: Differentially expressed transcript; FDR: False discovery rate; FPKM: Fragments per kilobase per million fragments mapped; GO: Gene ontology; KEGG: Kyoto encyclopedia of genes and genomes; KOG: euKaryotic orthologous groups; NGS: Next-generation sequencing; Nr: Non-redundant protein sequence; Pfam: Protein family; PG: Polygalacturonase; qRT-PCR: Quantitative real-time PCR; QTL: Quantitative trait locus; RNA-Seq: Ribonucleic acid sequencing; SNP: Single nucleotide polymorphism; Swiss-Prot: Annotated protein sequence database

\section{Acknowledgements}

We are grateful to B. Shaun Bushman from the USDA-FRRL for review of this manuscript, and we also thank Wenxian Liu for help with RNA-Seq data analysis.

\section{Funding}

This study was supported by grants from the Chinese National Basic Research Program (973 Program) (No. 2014CB138704), the Chinese National Natural Science Foundation (No. 31302023), the Open Project Program of State Key Laboratory of Grassland Agro-ecosystems, 111 program (B12002), and the Fundamental Research Funds for the Central Universities (LZUJBKY-2016-7).

\section{Availability of data and materials}

Raw Illumina reads are available in NCBI SRA: SRX2617497 (https:// www.ncbi.nlm.nih.gov/biosample/6545378). Other datasets supporting the conclusions of this article are included within the article and its additional files.

\section{Authors' contributions}

WX, YW and JZ conceived and designed the experiments. JZ and ZZ performed the sample collection and seed shattering evaluation. WX and JZ performed the transcriptome experiment. ZZ and XZ conducted histological and physiochemical experiments. WX and JZ analyzed the data and drafted the manuscript. WX, ZZ and YW revised the manuscript. All authors have read and approved the final manuscript.

\section{Authors' information}

All authors are affiliated with the State Key Laboratory of Grassland Agro-ecosystems, College of Pastoral Agriculture Science and Technology, Lanzhou University, Lanzhou, China.

\section{Competing interests}

The authors declare that they have no competing interests.

\section{Consent for publication}

Not applicable.
Ethics approval and consent to participate

Not applicable.

\section{Publisher's Note}

Springer Nature remains neutral with regard to jurisdictional claims in published maps and institutional affiliations.

Received: 23 January 2017 Accepted: 6 April 2017

Published online: 21 April 2017

\section{References}

1. Dong Y, Wang YZ. Seed shattering: from models to crops. Front Plant Sci. 2015;6:476. Available from: https://www.ncbi.nlm.nih.gov/pubmed/2615745. Accessed 7 May 2016.

2. Konishi S, Izawa T, Lin SY, Ebana K, Fukuta Y, Sasaki T, Yano M. An SNP caused loss of seed shattering during rice domestication. Science. 2006;312: 1392-1396. Available from: https://www.ncbi.nlm.nih.gov/pubmed/ 16614172. Accessed 7 May 2016.

3. Patterson SE. Cutting loose. Abscission and dehiscence in Arabidopsis. Plant Physiol. 2001;126:494-500. Available from: https://www.ncbi.nlm.nih.gov/ pubmed/11402180. Accessed 7 May 2016.

4. Elgersma A, Leeuwangh JE, Wilms HJ. Abscission and seed shattering in perennial ryegrass (Lolium perenne L.). Euphytica. 1988:39:51-57. Available from: https://link.springer.com/article/10.1007\%2FBF00043367. Accessed 7 May 2016.

5. Thurber CS, Hepler PK, Caicedo AL. Timing is everything: early degradation of abscission layer is associated with increased seed shattering in U.S. weedy rice. BMC Plant Biol. 2011;11:1-10. Available from: https://www.ncbi. nlm.nih.gov/pubmed/21235796. Accessed 7 May 2016.

6. Onishi KO, Takagi KT, Kontani MK, Tanaka T, Sano Y. Different patterns of genealogical relationships found in the two major QTLs causing reduction of seed shattering during rice domestication. Genome. 2007:50:757-766. Available from: https://www.ncbi.nlm.nih.gov/pubmed/17893735. Accessed 7 May 2016.

7. Pinyopich A, Ditta GS, Savidge B, Liljegren SJ, Baumann E, Wisman E, et al. Assessing the redundancy of MADS-box genes during carpel and ovule development. Nature. 2003;424:85-88. Available from: https://www.ncbi.nlm. nih.gov/pubmed/12840762. Accessed 7 May 2016.

8. Ogawa M, Kay P, Wilson S, Swain SM. ARABIDOPSIS DEHISCENCE ZONE POLYGALACTURONASE1 (ADPG1), ADPG2, and QUARTET2 are Polygalacturonases required for cell separation during reproductive development in Arabidopsis. Plant Cell. 2009;21:216-233. Available from: https://www.ncbi.nlm.nih.gov/pubmed/19168715. Accessed 7 May 2016

9. Li C, Zhou A, Sang T. Rice domestication by reducing shattering. Science. 2006;311:1936-1939. Available from: https://www.ncbi.n/m.nih.gov/pubmed/ 16527928. Accessed 7 May 2016

10. Ji H, Kim SR, Kim YH, Kim H, Eun MY, Jin ID, et al. Inactivation of the CTD phosphatase-like gene OsCPL1 enhances the development of the abscission layer and seed shattering in rice. Plant J. 2010;61:96-106. Available from: https://www.ncbi.nlm.nih.gov/pubmed/19807881. Accessed 7 May 2016.

11. Zhou Y, Lu D, Li C, Luo J, Zhu BF, Zhu J, et al. Genetic control of seed shattering in rice by the APETALA2 transcription factor shattering abortion 1. Plant Cell. 2012;24:1034-1048. Available from: https://www.ncbi.nlm.nih.gov/ pubmed/22408071. Accessed 7 May 2016.

12. Cai S, Lashbrook CC. Stamen abscission zone transcriptome profiling reveals new candidates for abscission control: enhanced retention of floral organs in transgenic plants overexpressing Arabidopsis ZINC FINGER PROTEIN2. Plant Physiol. 2008;146:1305-1321. Available from: https://www.ncbi.nlm.nih. gov/pubmed/18192438. Accessed 7 May 2016.

13. Meir S, Philosoph-Hadas S, Sundaresan S, Selvaraj KS, Burd S, Ophir R, et al. Microarray analysis of the abscission-related transcriptome in the tomato flower abscission zone in response to auxin depletion. Plant Physiol. 2010; 154:1929-1956. Available from: https://www.ncbi.nlm.nih.gov/pubmed/ 20947671. Accessed 7 May 2016.

14. Zhang MQ, Zhang JY, Liu ZP, Wang YR, Zhang L. Cloning and analysis of the MADS-box gene WM8 of Elymus nutans (in Chinese with English abstract). Acta Pratac Sin. 2015;21:141-150. Available from: http://en.cnki. com.cn/Article_en/CJFDTOTAL-CYXB201204018.htm. Accessed 7 May 2016.

15. Larson SR, Kellogg EA. Genetic dissection of seed production traits and Identifi cation of a major-effect seed retention QTL in hybrid Leymus 
(Triticeae) Wildryes. Crop Sci. 2009;49:29-40. Available from: https://dl. sciencesocieties.org/publications/cs/abstracts/49/1/29. Accessed 7 May 2016.

16. Xie WG, Zhao XH, Zhang JQ, Wang YR, Liu WX. Assessment of genetic diversity of Siberian wild rye (Elymus sibiricus L.) germplasms with variation of seed shattering and implication for future genetic improvement. Biochem Syst Ecol. 2015;58:211-218. Available from: http://dx.doi.org/10. 1016/j.bse.2014.12.006. Accessed 7 May 2016.

17. Ma X, Chen S, Zhang X, Bai S, Zhang C. Assessment of worldwide genetic diversity of Siberian wild rye (Elymus sibiricus L.) germplasm based on gliadin analysis. Molecules. 2012;17:4424-4434. Available from: https://www. ncbinlm.nih.gov/pubmed/22499189. Accessed 7 May 2016.

18. You MH, Liu JP, Bai SQ, Zhang XQ, Yan JJ. Study on relationship of seed shattering, seed development and yield traits of Elymus sibiricus L (in Chinese with English abstract). Southwest China J Agric Sci. 2011;24:12561260. Available from: http://lib.cqvip.com/qk/94396X/201104/39235151.html. Accessed 7 May 2016.

19. Zhao XH, Jiang X, Zhao K, Zhao XH, Yin J, Xie WG. Screening of germplasm with low seed shattering rate and evaluation on agronomic traits in Elymus sibiricus L. (in Chinese with English abstract). J Plant Genetic Resour. 2015;16: 691-699. Available from: http://lib.cqvip.com/qk/84467A/201504/665324662. html. Accessed 7 May 2016.

20. Liu W, Zhang Z, Chen S, Ma L, Wang H, Dong R, et al. Global transcriptome profiling analysis reveals insight into saliva-responsive genes in alfalfa. Plant Cell Rep. 2016;35:561-571. Available from: https://www.ncbi.nlm.nih. gov/pubmed/26645698. Accessed 7 May 2016.

21. Huang LK, Yan HD, Zhao XX, Zhang XQ, Wang J, Frazier T, et al. Identifying differentially expressed genes under heat stress and developing molecular markers in orchardgrass (Dactylis glomerata L.) through transcriptome analysis. Mol Ecol Resour. 2015;15:1497-1509. Available from: https:/www. ncbi.nIm.nih.gov/pubmed/25894804. Accessed 7 May 2016.

22. Ji HS, Chu SH, Jiang W, Cho YI, Hahn JH, Eun MY, et al. Characterization and mapping of a shattering mutant in rice that corresponds to a block of domestication genes. Genetics. 2006;173:995-1005. Available from: https:// www.ncbi.nlm.nih.gov/pubmed/16582442. Accessed 7 May 2016.

23. Grabherr MG, Haas BJ, Yassour M, Levin JZ, Thompson DA, Amit I, et al. Full-length transcriptome assembly from RNA-seq data without a reference genome. Nat Biotechnol. 2011;29:644-652. Available from: https://www.ncbi. nlm.nih.gov/pubmed/21572440. Accessed 7 May 2016.

24. Conesa A, Götz S, García-Gómez JM, Terol J, Talón M, Robles M. Blast2GO: a universal tool for annotation, visualization and analysis in functional genomics research. Bioinformatics. 2005;21:3674-3676. Available from: https://www.ncbi.nlm.nih.gov/pubmed/16081474. Accessed 7 May 2016.

25. Ye J, Fang L, Zheng H, Zhang Y, Chen J, Zhang Z, et al. WEGO: a web tool for plotting GO annotations. Nucleic Acids Res. 2006;34:293-297. Available from: https:/www.ncbi.nlm.nih.gov/pubmed/16845012. Accessed 7 May 2016.

26. Mortazavi A, Williams BA, McCue K, Schaeffer L, Wold B. Mapping and quantifying mammalian transcriptomes by RNA-seq. Nat Methods. 2008;5: 621-628. Available from: https://www.ncbi.nlm.nih.gov/pubmed/18516045. Accessed 7 May 2016.

27. Storey JD. A direct approach to false discovery rates. J R Stat Soc B. 2002;64: 479-498. Available from: https://www.jstor.org/stable/3088784. Accessed 7 May 2016.

28. Ernst J, Barjoseph Z. STEM: a tool for the analysis of short time series gene expression data. BMC Bioinformatics. 2006;7:191. Available from: https:// www.ncbi.nlm.nih.gov/pubmed/16597342. Accessed 7 May 2016.

29. Du Z, Zhou X, Ling Y, Zhang ZH, Su Z. agriGO: a GO analysis toolkit for the agricultural community. Nucleic Acids Res. 2010;38:64-70. Available from: https://www.ncbi.nlm.nih.gov/pubmed/20435677. Accessed 7 May 2016.

30. Xie C, Mao X, Huang J, Ding Y, Wu J, Dong S, et al. KOBAS 2.0: a web server for annotation and identification of enriched pathway $s$ and diseases. Nucleic Acids Res. 2011;39:316-322. Available from: https://www.ncbi.nlm. nih.gov/pubmed/21715386. Accessed 7 May 2016.

31. Livak KJ, Schmittgen TD. Analysis of relative gene expression data using real-time quantitative PCR and the $2^{-\Delta \Delta \mathrm{Ct}}$ method. Methods. 2001;25:402-408. Available from: https:/www.ncbi.nlm.nih.gov/pubmed/1 1846609. Accessed 7 May 2016.

32. Taylor JE, Whitelaw CA. Signals in abscission. New Phytol 2001; 151: 323339. Available from: http://onlinelibrary.wiley.com/doi/10.1046/j.0028-646x. 2001.00194.x/full. Accessed 7 May 2016.

33. Bunya-atichart K, Ketsa S, Doorn WG. Ethylene-sensitive and ethyleneinsensitive abscission in Dendrobium: correlation with polygalacturonase activity. Postharvest Bio Tec. 2011;60:71-74. Available from: http://www. sciencedirect.com/science/article/pii/S0925521410002619. Accessed 7 May 2016.

34. Huber DJ. The role of cell wall hydrolases in fruit softening. Hortic Rev. 1983;5:169-219. Available from: http://onlinelibrary.wiley.com/doi/10.1002/ 9781118060728.ch4/summary. Accessed 7 May 2016.

35. Xin ZJ, Wang Q, Yu ZN, Hu LC, Li JC, Xiang CY, et al. Overexpression of a Xylanase inhibitor Gene, OsHI-XIP, enhances resistance in Rice to herbivores. Plant Mol Biol Rep. 2014;32(2):465-475. Available from: https://www. researchgate.net/publication/258165018. Accessed 7 May 2016.

36. Robert JA, Elliott KA, Gonzalez-Carranza ZH. Abscission, dehiscence, and other cell separation process. Annu Rev Plant Biol. 2002;53:131-158. Available from: https://www.ncbi.nlm.nih.gov/pubmed/12221970. Accessed 7 May 2016.

37. Libertini E, Li Y, SJ MQ-M. Phylogenetic analysis of the plant endo- $\beta-1,4-$ glucanase gene family. J Mol Evol. 2004;58:506-515. Available from: https:// www.ncbi.nlm.nih.gov/pubmed/15170254. Accessed 7 May 2016.

38. Zhou HL, He SJ, Cao YR, Chen T, Du BX, Chu CC, et al. OsGLU1, a putative membrane-bound endo-1,4-beta-D-glucanase from rice, affects plant internode elongation. Plant Mol Biol. 2006; 60: 137-51. Available from: https://www.ncbi.nlm.nih.gov/pubmed/16463105. Accessed 7 May 2016

39. Nunes AL, Delatorre CA, Merotto Jr A. Gene expression related to seed shattering and the cell wall in cultivated and weedy rice. Plant Biol. 2014;16: 888-896. Available from: https://www.ncbi.nlm.nih.gov/pubmed/24597823. Accessed 7 May 2016.

40. Lashbrook CC, Gonzalez-Bosch C, Bennett AB. Two divergent endo- $\beta-1,4-$ glucanase genes exhibit overlapping expression in ripening fruit and abscising flowers. Plant Cell. 1994;6:1485-1493. Available from: https://www. ncbi.nlm.nih.gov/pubmed/7994180. Accessed 7 May 2016.

41. Ferrarese L, Trainotti L, Moretto P, Polverino de Laureto P, Rascio N, Casadoro G. Differential ethylene-inducible expression of cellulase in pepper plants. Plant Mol Biol. 1995;29:735-747. Available from: https://www.ncbi. nlm.nih.gov/pubmed/8541500. Accessed 7 May 2016.

42. Agrawal AP, Basarkar PW, Salimath PM, Patil SA. Role of cell wall-degrading enzymes in pod-shattering process of soybean, Glycine max (L.) Merrill. Current Sci. 2002;82:58-61. Available from: http://www.iisc.ernet.in/currsci/ jan102002/58.pdf. Accessed 7 May 2016.

43. Vasconcelos EA, Santana CG, Godoy CV, Seixas CD, SilvaMS MLR, et al. A new chitinase-like xylanase inhibitor protein (XIP) from coffee (Coffea arabica) affects soybean Asian rust (Phakopsora pachyrhizi) spore germination. BMC Biotechnol. 2011;11:14. Available from: https://www.ncbi. nlm.nih.gov/pubmed/21299880. Accessed 7 May 2016.

44. Goesaert H, Gebruers K, Courtin CM, Delcour JA. Purification and characterization of a XIP-type endoxylanase inhibitor from rice (Oryza sativa). J Enzym Inhib Med Chem. 2005;20:95-101. Available from: https:// www.ncbi.nlm.nih.gov/pubmed/15895691. Accessed 7 May 2016.

45. Durand A, Hughes R, Roussel A, Flatman R, Henrissat B, Juge N. Emergence of a subfamily of xylanase inhibitors within glycoside hydrolase family 18 . FEBS J. 2005;272:1745-1755. Available from: https://www.ncbi.nlm.nih.gov/ pubmed/15794761. Accessed 7 May 2016.

46. Tokunaga T, Esaka M. Induction of a novel XIP-type xylanase inhibitor by external ascorbic acid treatment and differential expression of XIP-family genes in rice. Plant Cell Physiol. 2007;48:700-714. Available from: https:// www.ncbi.nlm.nih.gov/pubmed/17379695. Accessed 7 May 2016.

47. Brown KM. Ethylene and abscission. Physiol Plantarum. 1997;100:567-576. Available from: http://onlinelibrary.wiley.com/doi/10.1111/j.1399-3054.1997. tb03062.x/pdf. Accessed 7 May 2016.

48. Sargent JA, Osborne DJ, Dunford SM. Cell separation and its hormonal control during fruit abscission in the Gramineae. J Exp Bot. 1984;35:16631674. Available from: http://www.jstor.org/stable/23691187. Accessed 7 May 2016.

49. Santiago J, Rodrigues A, Saez A, Rubio S, Antoni R, Dupeux F, et al. Modulation of drought resistance by the abscisic acid receptor PYL5 through inhibition of clade A PP2Cs. Plant J. 2009;60:575-588. Available from: https://www.ncbi.nlm. nih.gov/pubmed/19624469. Accessed 7 May 2016.

50. Fujii $\mathrm{H}$, Verslues $P E$, Zhu JK. Identification of two protein kinases required for abscisic acid regulation of seed germination, root growth, and gene expression in Arabidopsis. Plant Cell. 2007;19:485-494. Available from: https:/www.ncbi.nlm.nih.gov/pubmed/17307925. Accessed 7 May 2016.

51. Fujii $H$, Chinnusamy V, Rodrigues A, Rubio S, Antoni R, Park SY, et al. In vitro reconstitution of an abscisic acid signalling pathway. Nature. 2009;462:660- 
664. Available from: https://www.ncbi.nlm.nih.gov/pubmed/19924127. Accessed 7 May 2016.

52. Sexton R, Robert JA. Cell biology of abscission. Annu Rev Plant Biol. 1982;33: 133-162. Available from: http://www.annualreviews.org/doi/abs/10.1146/ annurev.pp.33.060182.001025. Accessed 7 May 2016.

53. Schaller $\mathrm{GE}$, Bleecker $\mathrm{AB}$. Ethylene binding sites generated in yeast expressing Arabidopsis ETR1 gene. Science. 1995;270:1809-1811. Available from: https:/ www.ncbi.nlm.nih.gov/pubmed/8525372. Accessed 7 May 2016.

54. Zhou D, Kalaitzis P, Mattoo AK, Tucker ML. The mRNA for an ETR1 homologue in tomato is constitutively expressed in vegetative and reproductive tissues. Plant Mol Biol. 1996;30:1331-1338. Available from: https://www.ncbi.nlm.nih.gov/pubmed/8704141. Accessed 7 May 2016.

55. Lashbrook CC, Tieman DM, Klee HJ. Differential regulation of the tomato ETR gene family throughout plant development. Plant J. 1998;15:243-252. Available from: https://www.ncbi.nlm.nih.gov/pubmed/9721682. Accessed 7 May 2016.

56. Hua J, Chang C, Sun Q, Meyerowitz EM. Ethylene insensitivity conferred by Arabidopsis ERS gene. Science. 1995;269:1712-1714. Available from: https:// www.ncbi.nlm.nih.gov/pubmed/7569898. Accessed 7 May 2016

57. Payton S, Fray RG, Brown S, Grierson D. Ethylene receptor expression is regulated during fruit ripening, flower senescence and abscission. Plant Mol Biol. 1996;31:1227-1231. Available from: https:/www.ncbi.nlm.nih.gov/ pubmed/8914538. Accessed 7 May 2016.

58. Roman G, Lubarsky B, Kieber JJ, Rothenburg M, Ecker JR. Genetic analysis of ethylene signal transduction in Arabidopsis thaliana: five novel mutant loci integrated into a stress response pathway. Genetics. 1995;139:1393-1409. Available from: https:/www.ncbi.nlm.nih.gov/pubmed/7768447. Accessed 7 May 2016.

59. Woodward AW, Bartel B. Auxin: regulation, action, and interaction. Ann Bot. 2005;95:707-735. Available from: https:/www.ncbi.nlm.nih.gov/pubmed/ 15749753. Accessed 7 May 2016.

60. Kant S, Bi YM, Zhu T, Rothstein SJ. SAUR39, a small Auxin-up RNA Gene, acts as a negative regulator of Auxin synthesis and transport in Rice. Plant Physiol. 2009;151:691-701. Available from: https://www.ncbi.nlm.nih.gov/ pubmed/19700562. Accessed 7 May 2016

61. Staswick PE, Serban B, Rowe M, Tiryaki I, Maldonado MT, Maldonado MC et al. Characterization of an Arabidopsis enzyme family that conjugates amino acids to indole-3-acetic acid. Plant Cell. 2005;17:616-627. Available from: https:/www.ncbi.nlm.nih.gov/pubmed/15659623. Accessed 7 May 2016.

62. Boerjan W, Ralph J, Baucher M. Lignin biosynthesis. Annu Rev Plant Biol. 2003;54:519-546. Available from: https://www.ncbi.nlm.nih.gov/pubmed/ 14503002. Accessed 7 May 2016.

63. Chen F, and Dixon R. Lignin modification improves fermentable sugar yield for biofuel production. Nat Biotechnol. 2007; 25: 759-61. Available from: https://www.ncbi.nlm.nih.gov/pubmed/17572667. Accessed 7 May 2016.

64. Yoon J, Cho LH, Kim SL, Choi HB, Koh HJ. An G. BEL1-type homeobox gene SH5 induces seed shattering by enhancing abscission zone development and inhibiting lignin biosynthesis. Plant J. 2014;79(5):717-728. Available from: https://www.ncbi.nlm.nih.gov/pubmed/24923192. Accessed 7 May 2016.

65. de Oliveira DM, Finger-Teixeira A, Mota TR, Salvador VH, Moreira-Vilar FC Molinari $\mathrm{HB}$, et al. Ferulic acid: a key component in grass lignocellulose recalcitrance to hydrolysis. Plant Biotechnol J. 2015;13(9):1244-1232. Available from: https://www.ncbi.nlm.nih.gov/pubmed/25417596. Accessed 7 May 2016

66. Li X, Weng JK, Chapple C. Improvement of biomass through lignin modification. Plant J. 2008;54:569-581. Available from: https://www.ncbi.nlm. nih.gov/pubmed/18476864. Accessed 7 May 2016.

67. Fu C, Mielenz JR, Xiao X, Ge Y, Hamilton CY, Rodriguez Jr M, et al. Genetic manipulation of lignin reduces recalcitrance and improves ethanol production from switchgrass. Proc Natl Acad Sci UAS. 2011;108:3803-3808. Available from: https://www.ncbi.nlm.nih.gov/pubmed/21321194. Accessed 7 May 2016.

68. Bouvier d'Yvoire M, Bouchabke-Coussa O, Voorend W, Antelme S, Cézard L, Legée F. Disrupting the cinnamyl alcohol dehydrogenase 1, gene (BdCAD1) leads to altered lignification and improved saccharification in Brachypodium distachyon. Plant J. 2013;73:496-508. Available from: https://www.ncbi.nlm. nih.gov/pubmed/23078216. Accessed 7 May 2016.
69. Rogers LA, Campbel MM. The genetic control of lignin deposition during plant growth and development. New Phytol. 2004;164:17-30. Available from: http://onlinelibrary.wiley.com/doi/10.1111/j.1469-8137.2004.01143.x/ full. Accessed 7 May 2016.

70. Zhao Q, Dixon RA. Transcriptional networks for lignin biosynthesis: more complex than we can though? Trends Plant Sci. 2011;16:227-233. Available from: https://www.ncbi.nlm.nih.gov/pubmed/21227733. Accessed 7 May 2016.

\section{Submit your next manuscript to BioMed Central and we will help you at every step:}

- We accept pre-submission inquiries

- Our selector tool helps you to find the most relevant journal

- We provide round the clock customer support

- Convenient online submission

- Thorough peer review

- Inclusion in PubMed and all major indexing services

- Maximum visibility for your research

Submit your manuscript at www.biomedcentral.com/submit
(O) BioMed Central 